\title{
Research on the Training Mode of the Integration of "Post, Competition and Training" in Vocational Colleges
}

Shulan $\mathrm{Yu}^{1, \mathrm{a}^{*}}$, Tianfang $\mathrm{Ma}^{1, \mathrm{~b}}$ and Fang $\mathrm{Li}^{1, \mathrm{c}}$

${ }^{1}$ Weifang Vocational College, Weifang, Shandong, 261041, China

Keywords: Vocational college; The integration of "post, competition and training"; Training mode; Research Abstract. In the context of the rapid development of vocational education in China, it is one of the most important teaching reform contents to explore the training mode of practical talents in vocational colleges. On the basis of the extensive professional research, according to the demand for talents in chemical industry, this paper constructs the integrated professional curriculum system and practice teaching system of "post, competition and training", orders the teaching content, and constructs the integrated teaching mode of "post, competition and training", which explores a new way to improve the quality of talent training in vocational colleges and to build the technical and skilled talents.

\section{职业院校 “岗赛训”一体化人才培养模式研究}

\author{
于淑兰，马天芳，李芳 \\ 潍坊职业学院，山东省 滩坊 261041
}

摘要: 在我国职业教育快速发展的背景下, 探索职业院校实用型人才培养模式是非常重要的教学改革内容之一。本文在 广泛专业调研的基础上，根据当前化工行业对人才的需求，构建了 “岗赛训”一体化的专业课程体系、实践教学体系，序化 了教学内容, 创建了 “岗赛训”一体化教学模式。为提高职业院校人才培养质量, 建设技术技能型人才, 探索一条新的途径。

关键词: 职业院校; “岗赛训”一体化; 培养模式; 研究

\section{1 引言}

目前, 我国的职业教育得到了快速发展。职业院校技能型人才培养既强调学生对理论知识的学习, 更 注重学生对实践技能的掌握, 即多元化人才培养途径已经成为职业教育发展的必然趋势 [1]。近几年, 很 多职业院校就技能型人才培养进行了探索, 但是在操作过程中的实践教学环节并未得到很好落实, 在实践 教学环节还难以适应企业的需求，使培养效果与技能型人才要求还存在一定差距 [2]。为了适应职业教育 的快速发展, 要求不断改革职业教育的人才培养模式。从职业教育这个角度而言, 职业院校应该怎样发挥 自身优势，培养适应社会经济发展需求、与企业接轨的实用型技能型人才，成为目前亟待解决的课题。本 研究旨在新的教育理念的指导下，改革已有的传统教学模式，构建符合当地产业结构需求的技术技能型人 才培养模式。即构建 “岗赛训”一体化的专业课程体系、实践教学体系、专业核心课程内容等人才培养模 式，满足化工企业对高技能人才的需求，为实现培养高素质技能型技术人才提供借鉴。

\section{2 “岗赛训”一体化人才培养模式的内涵}

“岗”是指职业岗位。职业岗位包含岗位职业标准、岗位工作任务和岗位职业能力等。职业教育的教 学目标、教学内容都要服务于 “岗”的要求。

“赛” 是指技能比赛。技能比赛包含赛技能和赛素质。通过开展多类型、多形式、多层次的技能比赛, 使学生熟练掌握专业的技术技能。 
“训” 是指训练操作技能。通过教学过程、生产过程、大赛训练过程对接的操作训练, 使学生具备较 强的综合应用能力。

“岗赛训” 一体化人才培养模式的实施, 就是通过教学组织学做一体, 技能比赛示范引领, 校企合作 共同育人，达到高素质技能型技术人才培养目标。

\section{3 构建 “岗赛训”一体化专业核心课程体系}

通过广泛的调查研究、毕业生反馈信息、职业技能标准和人才培养目标等进行综合分析, 确定应用化 工技术专业主要就业岗位及岗位任务, 经专家论证, 构建专业核心课程体系。专业核心课程体系流程见图 1 。

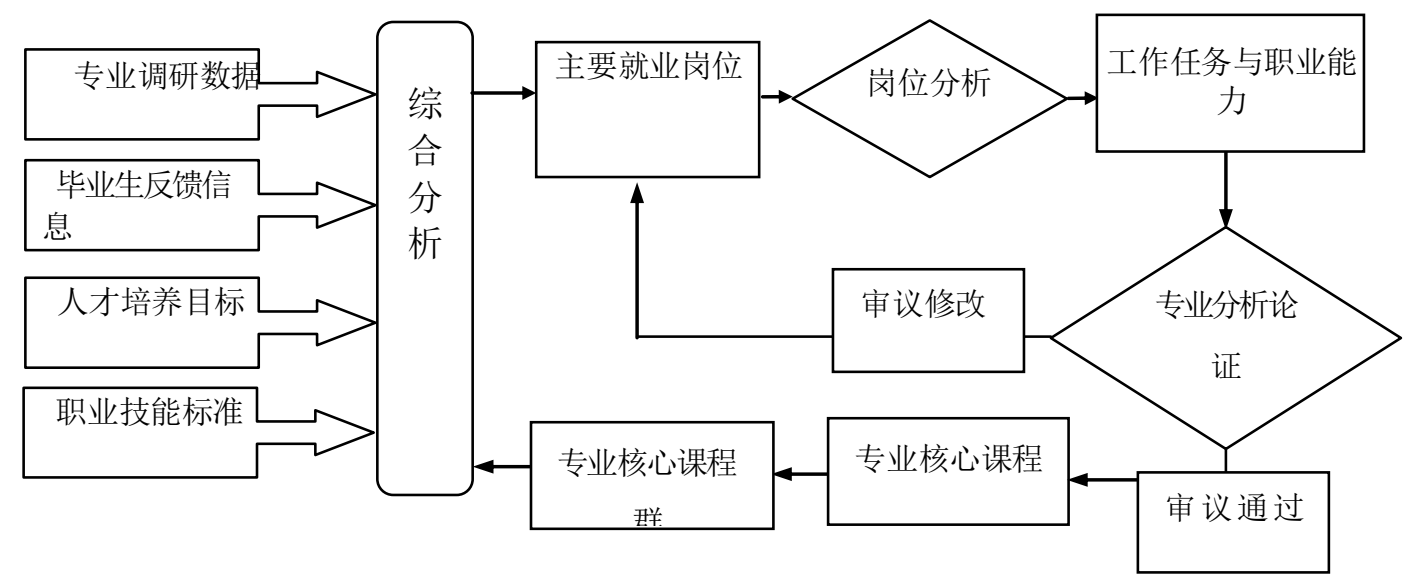

图 1 “岗赛训”一体化专业核心课程体系流程

专业课程体系以职业岗位需求为目标, 以国赛项目为引领, 以能力增进为主线, 经课程专家组提炼、 合并岗位工作任务, 最终设置《典型化工产品生产工艺运行》、《典型化工单元设备操作与控制》、《反 应器的选型与操作》、 《化工设备维护与检修》和《化工产品分析检测》5 门专业课程为应用化工技术专 业的核心课程。这五门课程彼此独立又相互关联, 涵盖了整个化工生产过程的工艺运行和设备操作控制。 学生通过该专业核心课程的学习, 不但掌握了化工典型产品完整的生产过程, 还提升了专业核心职业能力, 为迅速成长为一名优秀的技能型化工专业人才打下良好基础。

\section{4 构建 “岗赛训”一体化实践教学体系}

“岗赛训”一体化实践教学体系构建的原则是：知识、技能和素质教育相贯通, 提升学生综合职业能 力。在实践教学过程中, 既要注重学生职业技能的培养, 又要加强职业素质的培养, 一定要体现出职业素 质培养的重要性, 使学生明白职业素质是在毕业后工作中必备的基本素质 [3]。

\section{1 设计与技能比赛项目相匹配的专业实践教学内容}

根据技能比赛项目内容, 对接岗位技能要求, 设置与技能比赛项目相匹配的实践教学内容。即技能比 赛内容融入实践教学中, 使实践教学与技能比赛相统一, 达到以学促赛、以赛促学及 “学赛”一体的教学 目标, 设计与技能比赛项目相匹配的实践教学内容组成构架见表 1 。 


\section{表 1 与技能比赛项目相匹配的实践教学内容组成构架}

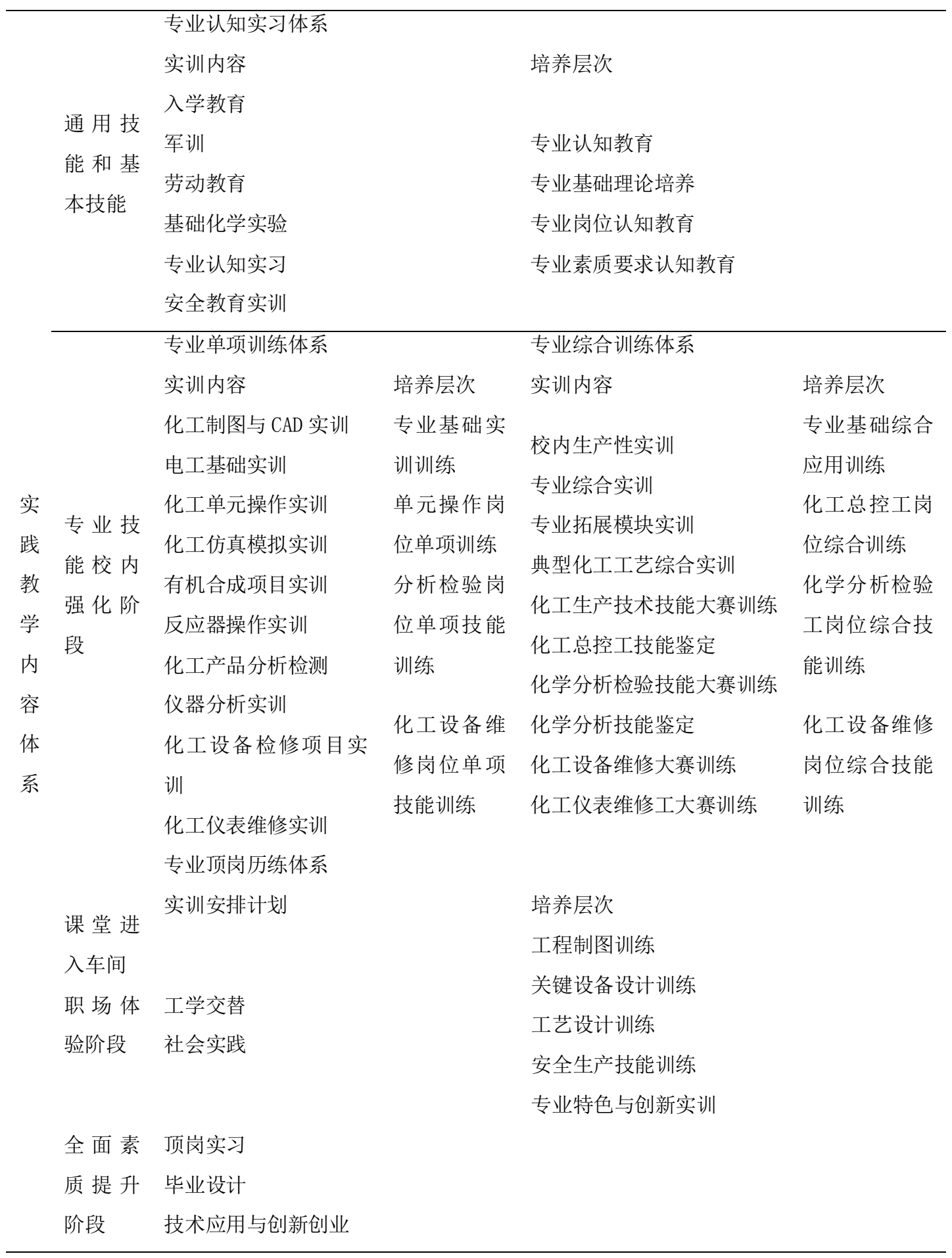

\section{2 构建与技能比赛项目对接的实践教学体系}

按照 “职业性、实践性、开放性” 原则，实施 “基本职业技能 $\rightarrow$ 专业职业技能 $\rightarrow$ 综合职业技能” 技能 逐级递进、能力逐次提升的实践教学内容, 进行实践教学体系的构建。该实践教学体系以职业岗位需求为 依据, 以岗位职业能力培养为核心, 以技能比赛项目（化工生产技术、化工设备维修、化工仪表自动化、 分析检验）为引领，根据岗位工作任务和职业能力分析，校企共同构建职业素质基础模块、大赛单项专业 技能训练、大赛综合专业技能训练、职业能力提升的顶岗历练四层次 “岗赛训”一体化实践教学体系（见 图 2)。 


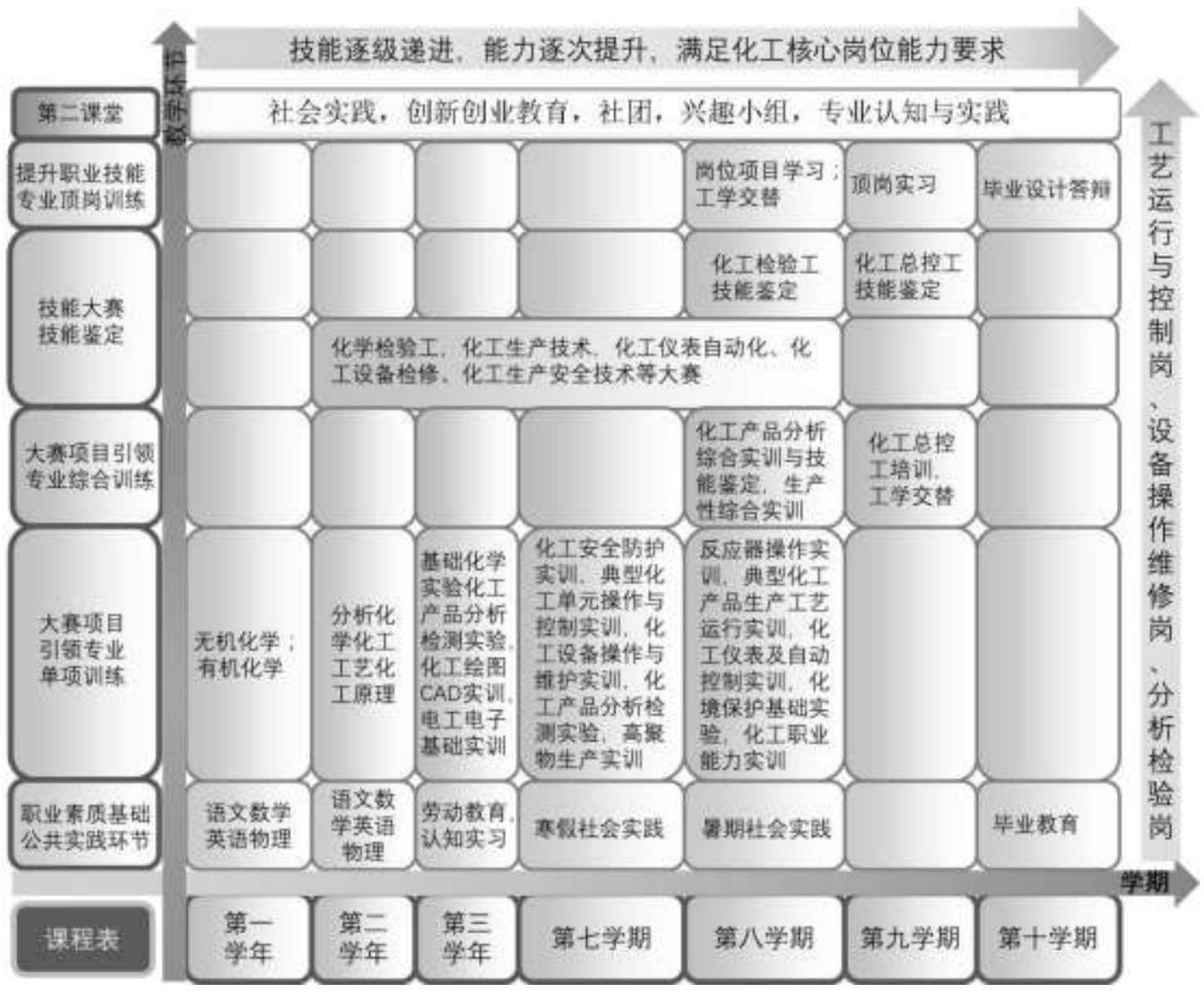

图 2 “岗赛训”一体化实践教学体系

\section{5 以职业能力培养为核心，序化教学内容}

职业教育课程教学内容应该把培养学生的职业能力放在首位, 引入企业工程技术实例和技能比赛项目 案例, 通过校企合作制度化 [4], 将企业所需的专业技术技能、企业文化、技能比赛内容、职业资格标准 和职业素质纳入教学内容中。构建以职业岗位能力培养为主线的实践课程内容, 使岗位能力培养、技能训 练、多层次技能比赛能够更好的结合融通。

以《典型化工单元操作与控制》课程为例, 序化教学内容。该课程依据化工生产技术赛项的仿真及精 馏操作内容, 将化工反应工程和化工原理两门课程的实训内容进行整合。包含换热器操作与控制、传质设 备操作与控制操作和反应器操作与控制等的典型设备的操作。再将每个典型设备操作过程按顺序划分为若 干任务, 根据完成每个任务所需要的知识、技能和素质, 融入职业技能、企业元素和技能比赛相关的内容, 形成与技能大赛紧密对接的课程体系。该课程体系涵盖了典型设备从开车前准备、开车、稳定运行、停车 以及事故处理等方面的全部知识技能。该课程的学习培养了学生的设备操作能力, 故障分析与解决问题的 能力。

\section{6 创建 “岗赛训”一体化教学模式}

以岗位职业能力培养为主线, 以工学结合为切入点, 以职业技能大赛为引领, 按照 “岗位任务 $\rightarrow$ 实训 项目 $\rightarrow$ 比赛项目任务” 和 “学生 $\rightarrow$ 准员工 $\rightarrow$ 员工” , 创新设计 “三环相扣、五位一体” 的 “岗赛训”一体 化教学模式（见图 3)。 


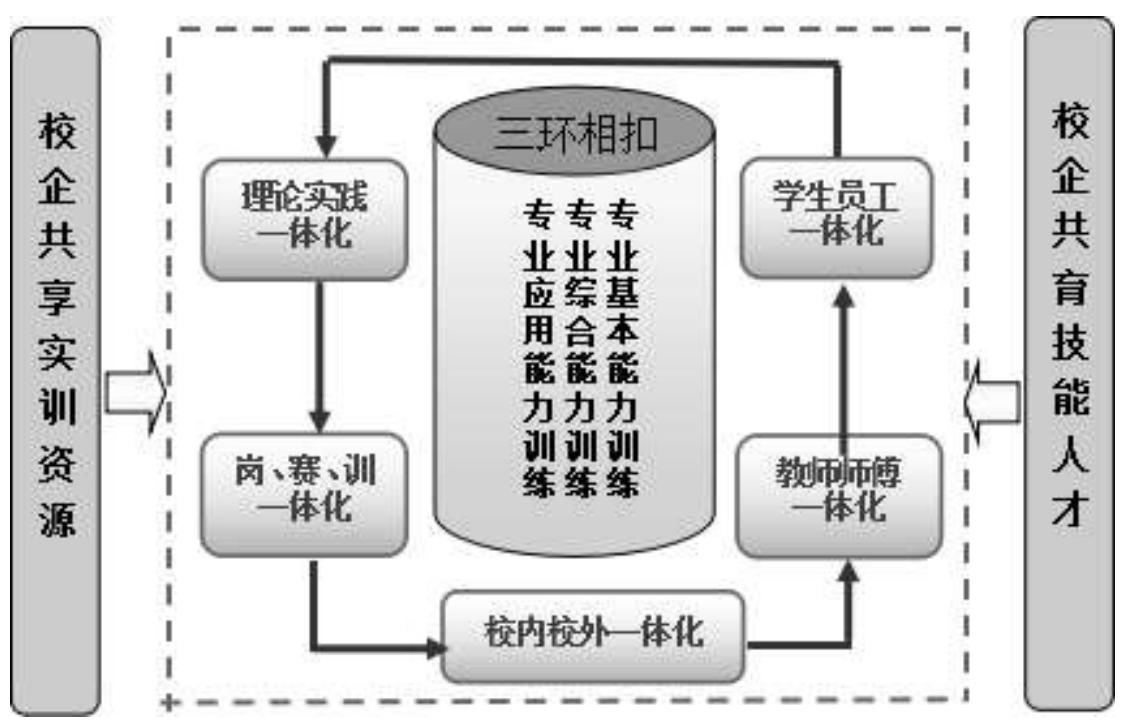

图 3 “三环相扣、五位一体”的 “岗赛训”一体化教学模式

通过设置企业任务场景、下达工作任务、进行任务资讯、任务训练和技能比赛考核等过程，实现理论 与实践的一体化, 岗、赛、训的一体化, 校内与校外的一体化, 教师与师傅的一体化, 学生与员工的一体 化的教学模式。该教学模式使基本职业能力、综合职业能力、应用职业能力的培养环环相扣, 有效解决了 教学过程与工作过程脱节、学习项目与工作任务不符、学生培养与工匠培养脱节的问题, 达到培养高素质 技术技能型人才的目的。

\section{7 结语}

在职业教育快速发展的今天, 人才培养模式多样化是形势发展的需要。根据这一特点, 经过近几年的 不断努力, 构建了 “岗赛训”一体化的专业课程体系、实践教学体系, 序化了教学内容, 创建了 “岗赛训” 一体化教学模式。该教学模式有利于技能型人才的培养, 有利于学生全面能力的提高, 可为职业院校的建 设探索新的教学途径。

\section{参考文献:}

[1] 张鹏飞. 地方院校本科应用型人才培养现状、问题与策略 [J]. 湖北工程学院学报, 2014.9.

[2] 王佳莉，王慧㜆. 高等学校招生模式改革评价模型 $[\mathrm{J}]$. 统计与咨询， 2013. 3.

[3] 张千里. 校内实践教学管理与技能型应用型人才培养探析[J]。中国电力教育， 2010 (4)：158-159.

[4] 徐长君. 校企合作订单班的管理体系探索 [J]. 价值工程, 2015. 3.

\section{References}

[1] P.F.Zhang: The Current Situation, Problems and Strategies for the Training of Applied Talents in Local Colleges and Universities[J], Journal of Hubei Engineering University, 2014.9.(In Chinese)

[2] J.L.Wang and H.X.Wang: Evaluation Model of College Enrollment Mode Reform[J], Statistics and Consultation, 2013.3.(In Chinese)

[3] Q.L.Zhang: Analysis of the Management of Practical Teaching in School and the Training of Skilled Applied Talents[J], China Electric Power Education, 2010(4): 158-159.(In Chinese)

[4] C.J.Xu: The Exploration of the Management System of the School-Enterprise Cooperation Order Class[J], Value Engineering, 2015.3.(In Chinese) 